\title{
Left Ventricular Diastolic Function in Hypertension: Methodological Considerations and Clinical Implications
}

\author{
Pasquale Palmiero ${ }^{\mathrm{a}, \mathrm{i}}$, Annapaola Zito ${ }^{\mathrm{b}}$, Maria Maiello ${ }^{\mathrm{a}}$, Matteo Camelic ${ }^{\mathrm{c}}$, Pietro Amedeo Modesti ${ }^{\mathrm{d}}$, Maria \\ Lorenza Muiesan $^{\mathrm{e}}$, Salvatore Novo ${ }^{\mathrm{f}}$, Pier Sergio Saba ${ }^{\mathrm{g}}$, Pietro Scicchitano ${ }^{\mathrm{b}}$, Roberto Pedrinelli ${ }^{\mathrm{h}}$, \\ Marco Matteo Ciccone , on behalf of the Gruppo di Studio "Ipertensione, Prevenzione e Riabilitazione" della \\ Societa Italiana di Cardiologia
}

\begin{abstract}
The assessment of left ventricular (LV) diastolic function should be an integral part of a routine examination of hypertensive patient; indeed when LV diastolic function is impaired, it is possible to have heart failure even with preserved LV ejection fraction. Left ventricular diastolic dysfunction (LVDD) occurs frequently and is associated to heart disease. Doppler echocardiography is the best tool for early LVDD diagnosis. Hypertension affects LV relaxation and when left ventricular hypertrophy $(\mathrm{LVH})$ occurs, it decreases compliance too, so it is important to calculate Doppler echocardiography parameters, for diastolic function evaluation, in all hypertensive patients. The purpose of our review was to discuss about the strong relationship between LVDD and hypertension, and their relationship with LV systolic function. Furthermore, we aimed to assess the relationship between the arterial stiffness and LV structure and function in hypertensive patients.
\end{abstract}

Keywords: Left ventricular; Diastolic function; Diastolic dysfunction; Hypertension

\section{Introduction}

Left ventricular diastolic dysfunction (LVDD) is an earlier

Manuscript accepted for publication December 10, 2014

${ }^{a} A S L$ Department of Cardiology, Brindisi District, Italy

${ }^{b}$ Cardiovascular Disease Section, Department of Emergency and Organ Transplantation, University of Bari, Italy

'Department of Cardiovascular Diseases, University of Siena, Italy

${ }^{\mathrm{d}}$ Department of Clinical and Experimental Medicine, University of Florence, Florence, Italy

${ }^{e}$ Clinica Medica, Department of Clinical and Experimental Sciences, University of Brescia, Brescia, Italy

fDepartment of Internal Medicine and Cardiovascular Diseases, Palermo, Italy ${ }^{g}$ Cardiologia, Azienda Ospedaliero-Universitaria di Sassari, Italy

hDipartimento di Patologia Chirurgica, Medica, Molecolare e dell'Area Critica, Universita di Pisa, Pisa, Italy

${ }^{\mathrm{i} C}$ Corresponding Author: Pasquale Palmiero, ASL Department of Cardiology, Brindisi District, Italy. Email: pasqualepalmiero@yahoo.it

doi: http://dx.doi.org/10.14740/jocmr2050w alteration common to many cardiovascular diseases $[1,2]$. Any kind of heart disease that leads to myocardial structural alteration and/or pericardial effusion may cause LVDD [1-3]. Sometimes this structural abnormality is evident macroscopically (i.e. hypertrophy, fibrosis, infiltrative diseases, dilated cardiomyopathy, myocardial infarction, constrictive pericarditis, etc.). Other times, diastolic dysfunction is linked to abnormalities of the cellular mechanisms of myocyte relaxation caused by hypoxia and/or ischemia [3]. A lot of patients with congestive heart failure, symptomatic, have a normal left ventricular ejection fraction and signs/symptoms mainly due to diastolic dysfunction $[4,5]$. For these reasons, the assessment of LV diastolic function should be always performed during a routine echocardiographic examination, since when LV diastolic function is impaired, it is possible to have heart failure even with preserved LV ejection fraction (HFpEF). Diastolic dysfunction can display a wide spectrum of different patterns, ranging from a simple slowing of ventricular relaxation, without significant hemodynamic changes, to the development of pulmonary venous congestion, due to elevation of ventricular diastolic pressures with displacement of the pressure-volume loop in the upper and to the left [2,3] (Fig. 1). However, patients affected by heart failure often presents both systolic and diastolic ventricular dysfunction, since the systole and diastole are related one to the other in a complex way. Often changes in diastolic function do not affect only the filling of the ventricles, but also ventricular systolic function [6]. Many factors

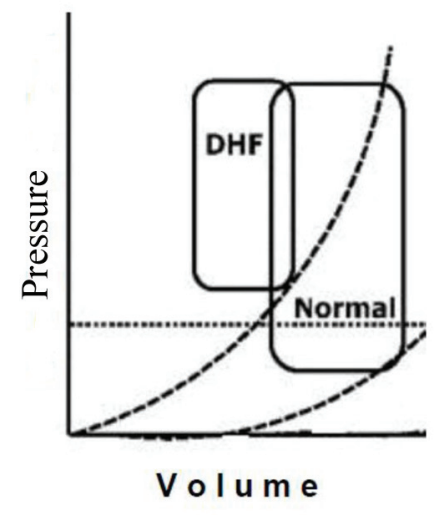

Figure 1. Pressure/volume loop in LVDD. 


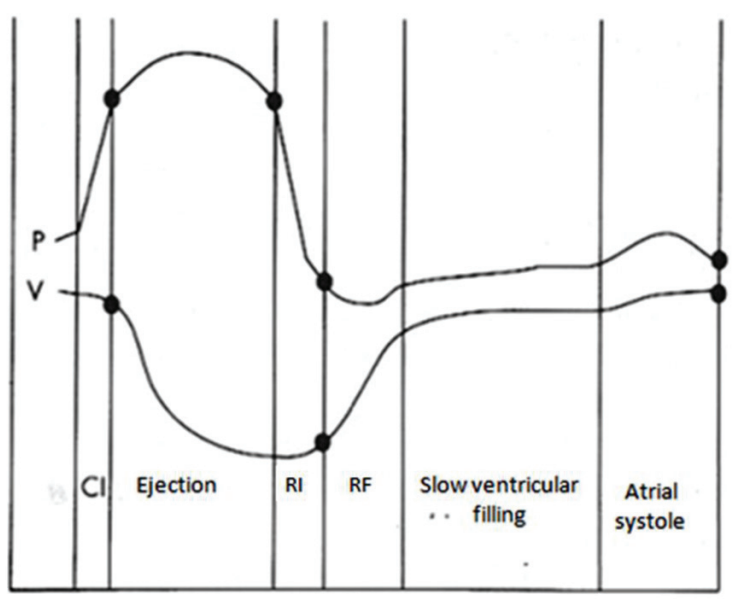

Figure 2. Diastolic phases related with changes in pressure $(\mathrm{P})$ and volume $(\mathrm{V})$ during a cardiac cycle. Cl: isovolumic contraction; $\mathrm{RI}$ : isovolumic relaxation; RF: rapid filling.

can influence the ventricular diastolic filling and then the diastolic pressure-volume relationship: coronary insufficiency [7], vasodilators and vasoconstrictors [8] (i.e. changes in preload and after load), geometric-mechanical interactions between the ventricles (e.g. reverse Bernheim effect in pulmonary embolism) [9], pericardial anatomy [10] (e.g. constrictive pericarditis, pericardial effusion), metabolic alterations (acidosis, alkalosis) [11], cardiovascular drugs [12] (e.g. digital, betablockers, calcium channel blockers), and hypoxia [13].

To better understand how LVDD occurs, we have to start from physiopathology of LV diastole. It can be divided into four phases, starting from aortic valve closure. The first phase of diastole is the isovolumic, which does not contribute to ventricular filling. The second of early and rapid filling provides most of ventricular filling, about $60-90 \%$. The third of slow filling, mentioned as diastasis, contributes to only $5 \%$ of the total filling. The final atrial booster phase normally accounts for the remaining 5-35\%, according to the age, with an increasing contribution in elderly [14] (Fig. 2).

"Isovolumic relaxation time" starts with the closure of the semilunar valves and ends with the opening of the atrioventricular ones. During this phase, there is no change in intraventricular volume (because the valves are closed), but the geometric configuration of the ventricular cavity changes, followed by a fall in ventricular pressure that becomes lower than atrial pressure. Then atrioventricular valve opens and it begins the second phase of diastole: fast ventricular filling [15]. The isovolumic relaxation is an energy-dependent process, where the calcium ions are removed from the cytoplasm against a concentration gradient, allowing the dissociation of the contractile complex actin-myosin (active relaxation) [16]. It can be influenced, not only by the anatomical and functional heart conditions, but even from pre-load and post-load. The speed of relaxation also influences the speed of fall of left ventricular pressure. An impaired relaxation causes an increase in filling pressure to maintain an adequate diastolic volume of the ventricle. Even the "elastic recovery" (the release of elastic energy "compressed" in the myocardium during the previous systole and then released as soon as the relaxation begins) acts on the isovolumic relaxation. Also this release contributes to the fall of left ventricular pressure at the beginning of diastole. A reduction in systolic function, resulting in an increase in left ventricular end-systolic volume, causes a reduction of the "elastic return" in the subsequent early diastole. The gold standard measurement of relaxation rate is $\mathrm{dP} / \mathrm{dtmax}$, but it requires invasive catheterization [17]. Similarly, tau, the time constant of relaxation, describes the rate of LV pressure decrease during isovolumic relaxation but it requires invasive techniques [1820]. On clinical practice, tau is assessed by echocardiography. Tau is increased as the systolic LV pressure increases. The isovolumic relaxation time can be measured by Doppler echocardiography: it lies between aortic valve closure and mitral valve opening, but it suffers of an high intra- and inter-operator variability, so the range of normality is wide [20].

"Ventricular fast filling time" starts with the opening of the atrioventricular valve, proceeds with increasing speed up to a maximum peak, subsequently decelerates, and ends with the beginning of the third phase. During this phase, the blood which had accumulated in the atrium while the valve was closed is poured rapidly into the ventricle, consequently the atrial pressure falls while the ventricular pressure increases. The contribution of rapid ventricular filling to total diastolic one, in healthy adults, is about $65-80 \%$ [21]. "Fast ventricular filling time" is a mainly passive process, due to the atrioventricular gradient, that is greatly influenced by ventricular compliance. This phase of diastole is also influenced by the "elastic return" of the ventricle. In the "slow ventricular filling", the flow of blood from the atrium to the ventricle is very slow, because the pressure gradient atrioventricular is virtually absent. The duration of this phase is greatly dependent on the heart rate [18-21]. "Atrial systole" is the final phase of diastole, present only on sinus rhythm. Atrial active contraction causes an increase of blood flow from the atrium to the ventricle, consequently an increase in pressure and volume occurs and the end-diastolic ventricular activation of Starling's effect happens [4]. In normal subject, the contribution of atrial systole to the 


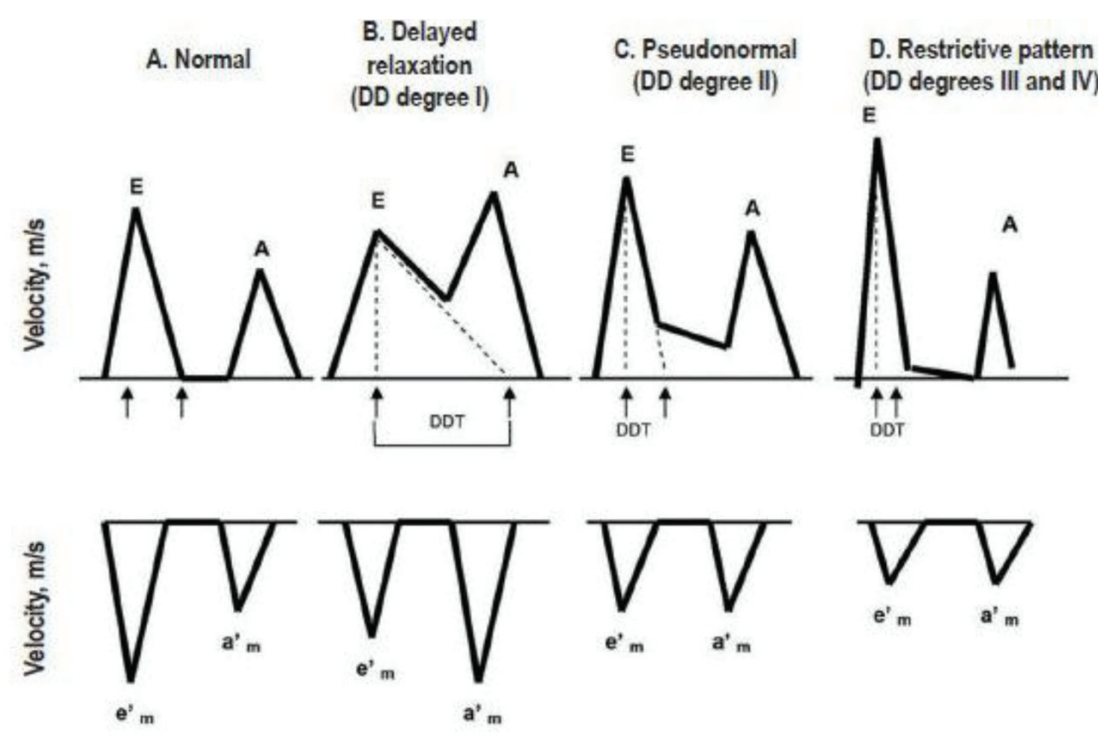

Figure 3. Different patterns of LVDD by transmitral flow pattern (upper) and tissue Doppler at mitral annulus level (lower). DDT: diastolic deceleration time, $E$ and $e_{m}^{\prime}$ : early ventricular filling; $A$ and $a_{m}^{\prime}$ : atrial contraction.

total LV filling is about $20 \%$. An increase in heart rate reduces the contribution of atrial systole. In arterial hypertension, LV filling abnormalities can be detected early and also, often, they precede the impairment of systolic function of the left ventricle. In all phases of diastole, hypertension affects relaxation and when left ventricular hypertrophy (LVH) occurs, it reduces compliance too, so it is important to calculate Doppler echocardiography parameters, for diastolic function evaluation, in all hypertensive patients. The goal of our paper is to assess the strong relationship between LVDD and hypertension, and their relationship with LV systolic function. We also want to investigate if there is a relation between the arterial stiffness and LV structure and function in hypertensive patients [22, 23].

\section{The Assessment of LV Diastolic Function}

LVDD is an important predictor of symptoms and clinical outcomes in patients with left ventricular systolic dysfunction (LVSD) $[1,2,24]$. Abnormalities of diastolic function in this population include an increase in LV filling pressures and LV volumes and impaired LV relaxation [25]. In a recent paper, "pre-clinical diastolic dysfunction" (PDD) has been defined as LVDD without congestive heart failure diagnosis and with normal systolic function [3]. Although invasive measures of LV relaxation and LV filling pressures (i.e., LV end-diastolic pressure) are considered to be the "gold standards" for the assessment of diastolic function, they are not performed in stable outpatients with LVSD. Pulsed-wave Doppler (PWD)-derived transmitral inflow patterns are commonly used for assessment of LVDD [26-28].

However, patients with LVSD often have variability in PWD-derived indices of LVDD due to increases in LA pressure, so they are preload-dependent [29, 30]. Tissue Doppler imaging (TDI)-derived early diastolic mitral annular velocity
(E') and color M-mode (CMM) imaging flow propagation velocity $(\mathrm{Vp})$ have been reported to be less load-dependent methods to assess LV relaxation [31-33].

In addition, the diastolic intraventricular pressure gradient (IVPG) can be derived from CMM imaging by mathematical calculations of the spatio-temporal distribution of the early diastolic blood flow velocities into the LV cavity [34, 35]. IVPG is reported to be a relatively preload-independent measurement of $L V$ relaxation $[36,37]$. The evaluation of diastolic function by TDI and CMM-derived measurements to assess diastolic function in patients with LVSD has not been well evaluated. The measurement of these myocardial parameters could be of great importance in patients with HFpEF because these echocardiographic indices well describe the multidirectional function of whole LV myocardium, thereby allowing a detection of LV global function affections that is associated with a worse in symptomatic status of these patients.

\section{LVDD and Prognosis}

LVDD develops early in most cardiac diseases and leads to the elevation of LV filling pressures. Therefore, echocardiographic measurements of diastolic function provide important prognostic information. E/A ratios (early phase of atrial filling phases) reflect the compensatory increase in the late (atrial) filling phase when hypertrophic LV fails to relax normally during diastole. The result is that the E/A ratio on the mitral Doppler pattern decreases or reverses. However, when LV hypertrophy increases and wall fibrosis develops, LV chamber compliance decreases and the $\mathrm{E}$ wave again rises. Thus, it becomes difficult to separate E/A ratios that are truly normal from pseudonormal patterns of mitral inflow. Doppler tissue can measure the actual velocity of tissue relaxation of the mitral valve annulus or the posterior wall. Clinical studies have 
shown the association of short mitral diastolic deceleration time (DDT) with heart failure, death and hospitalizations in patients with acute myocardial infarction [38-54] (Fig. 3). Diastolic measurements provide incremental information to wall motion score index, as assessed by a recent meta-analysis of 12 post-acute myocardial infarction studies involving 1,286 patients [55]. Similar findings were reported in patients with ischemic or dilated cardiomyopathy, including atrial fibrillation. Pulmonary venous velocities [42, 56-58] and Vp [59] were less frequently performed but were still predictive of clinical events $[60,61]$. Given the variability in measuring DT, Vp, and pulmonary venous flow velocity duration, recent studies have examined the prognostic value of $\mathrm{E} / \mathrm{E}^{1}$. Several studies [62-74] have shown that $\mathrm{E} / \mathrm{E}^{1}$ is highly predictive of adverse events after acute myocardial infarction and in hypertensive cardiomyopathy, severe secondary mitral regurgitation (MR), end-stage renal disease, atrial fibrillation, and cardiomyopathic disorders. The $\mathrm{E} / \mathrm{E}^{1}$ ratio is among the most reproducible echocardiographic parameter to estimate pulmonary capillary wedge pressure and is the preferred prognostic parameter in many cardiac conditions. While all Doppler parameters abovementioned estimate LVDD at moment of the performance, left atrial structural and functional remodeling parameters have been proposed as a barometer of diastolic burden over time and as predictor of common cardiovascular outcomes, such as atrial fibrillation, stroke, congestive heart failure, and cardiovascular death $[75,76]$.

\section{Aortic stiffness}

Aortic stiffening is increasingly recognized as an early marker of future cardiovascular disease and mortality among general population and hypertensive patients [77-80].

Classic risk scores may underestimate the risk of cardiovascular events in specific groups suitable for early prevention, such as asymptomatic hypertensive patients, often being wrongly classified as at low or moderate risk. Arterial stiffness is the most important determinant of increasing systolic and pulse pressures in ageing societies, thus giving a relevant contribution to incidence of stroke and myocardial infarction. Arterial stiffness has a predictive value for cardiovascular events, beyond classical cardiovascular risk factors and gives direct evidence of target organ damage, being itself a "tissue biomarker" [81]. Increased aortic stiffness is considered to be involved into artery's ageing process [79], it determinates an increase in systolic blood pressure (SBP) and a decrease in diastolic blood pressure (DBP) resulting in an augmented LV workload and reduced perfusion of the coronary arteries during diastole [81]. Increased aortic stiffness, a major mechanical factor predicting CV risk, has been well identified as playing a role in metabolic syndrome. Its age progression seems to be proportional to the number of risk factors involved in metabolic syndrome and is responsible for increased SBP and decreased DBP with increasing age, the principal hallmarks of hypertension in the elderly [78]. Aortic stiffness is assessed by PWVg measured using two-dimensional (2D) echocardiography. The PWVg is calculated between the aortic valve and right common femoral artery by dividing the straight line distance between the two by the transit time. The distance is assessed using a tape measure located at the same place as the ultrasound probe. The transit time was defined as the difference between two intervals of time using the Doppler method [82]. PWVg is a simple, accurate, noninvasive means for the determination of large-artery stiffness, and it does not require dedicated equipment because it is performable by common echocardiographic machine, does not need training and is not time consuming [80]. Aortic PWV is considered an intrinsic measure of arterial stiffness according to the Moens-Korteweg equation where PWV is proportional to the square root of the incremental elastic modulus, of the vessel wall given constant ratio of wall thickness, to vessel radius and blood density, assuming that the artery wall is isotropic and experiences isovolumetric change with pulse pressure [80]. So PWV is related to the pulsatile component of LV afterload and is linked to prognostically adverse cardiac phenotype, including depressed LV systolic function $[83,84]$. The strong relation between PWV and LV is also true because the pulse wave is generated by the contracting heart, and aortic PWV might be partially determined by enhanced myocardial performance, with a shortened LV ejection time, in young subjects [82]. If the initial speed of the pressure wave is mainly determined by the velocity of myocardial shortening [85] and LV ejection time is related with shortening velocity [86], we can assess that myocardial function and pulse pressure influence each other. The relation between aortic PWV and LV mass and function have been understudied until recent years. However, it may support a better comprehension of mechanism of HFpEF, a condition associated with high morbidity and mortality, whose prevalence is increasing, and is common among postmenopausal women. There are sex differences in aortic stiffness and its influence on left ventricle mass, geometry and function, postmenopausal women display increased arterial and LV stiffening, so LVDD $[87,88]$. In addition, the association of increased arterial stiffness with mortality is almost two-fold higher in women than in men [89].

\section{Conclusions}

Although LVDD remains poorly understood, it has an important clinical significance. LV diastolic function is influenced by arterial stiffness, changing the different components of its load, modulates LV structure and function. In patients affected by arterial hypertension, the pressure-volume loop shifts to the upper right side, therefore, pulmonary congestion is induced by a significant increase in LV end-diastolic pressure. To preserve LV ejection fraction, the pressure-volume loop shifts right due to a preload increase. Therefore, the LV pressure-volume loop operates on the ascending section of the end-diastolic pressurevolume curve, consequently causing end-diastolic pressure to arise. There is a strong relationship between arterial stiffness and the diastolic properties of the left ventricle. With increasing age, arterial stiffness becomes related to LV hypertrophy and to impaired LV diastolic function $[77,78,90]$. Aortic stiffness is related to electrocardiographically determined LVH in 
patients with hypertension [79]. Aortic PWVg is widely used to estimate arterial stiffness as elastic properties of the arterial tree and it is a strong predictor of cardiovascular outcomes in different clinical settings, including essential hypertension [91, 92]. Large artery stiffness is related to an array of functional and structural changes of the left ventricle [88, 93-95]. An elevated aortic impedance is a major stimulus for the development of LV unfavorable changes in diastolic function and a significant increase in LV mass. The more possible complete study of LV diastolic function and arterial stiffness leads to a complete detection of different mechanisms involved into complex functional and structural modifications of the hypertensive heart.

\section{References}

1. Wiegers SE. Diastolic echo parameters: meaningless numbers or crucial information? Circ Cardiovasc Imaging. 2011;4(5):460-462.

2. Nagueh SF, Appleton CP, Gillebert TC, Marino PN, Oh JK, Smiseth OA, Waggoner AD, et al. Recommendations for the evaluation of left ventricular diastolic function by echocardiography. Eur J Echocardiogr. 2009;10(2):165193.

3. Wan SH, Vogel MW, Chen HH. Pre-clinical diastolic dysfunction. J Am Coll Cardiol. 2014;63(5):407-416.

4. Zile MR, Baicu CF, Gaasch WH. Diastolic heart failure-abnormalities in active relaxation and passive stiffness of the left ventricle. N Engl J Med. 2004;350(19):19531959.

5. Vasan RS, Levy D. Defining diastolic heart failure: a call for standardized diagnostic criteria. Circulation. 2000;101(17):2118-2121.

6. Quiroz R, Doros G, Shaw P, Liang CS, Gauthier DF, Sam F. Comparison of characteristics and outcomes of patients with heart failure preserved ejection fraction versus reduced left ventricular ejection fraction in an urban cohort. Am J Cardiol. 2014;113(4):691-696.

7. Mitu F, Mitu M. [Clinical aspects of the left ventricular diastolic dysfunction at patients with coronary heart disease]. Rev Med Chir Soc Med Nat Iasi. 2001;105(4):733739.

8. Wang J, Guan W, Chen D, Han Y, Xu Z, Qiang J, Chen W, et al. The value of CTPA for diagnosing acute pulmonary thromboembolism and the ensuing right ventricular dysfunction. Cell Biochem Biophys. 2014;69(3):517-522.

9. McCabe C, White PA, Hoole SP, Axell RG, Priest AN, Gopalan D, Taboada D, et al. Right ventricular dysfunction in chronic thromboembolic obstruction of the pulmonary artery: a pressure-volume study using the conductance catheter. J Appl Physiol (1985). 2014;116(4):355-363.

10. Morishima S, Sakai H, Okazaki A. [Anesthetic management of a hemodialysis patient presenting with apparent LV diastolic dysfunction after undergoing extensive pericardiectomy for constrictive pericarditis]. Masui. 2014;63(2):175-179.

11. Nogueira JB. [Hypertensive cardiopathy. From arterial hypertension to congestive heart failure]. Rev Port Cardiol. 1999;18(6):635-646.

12. Lim S, Chang W, Cha MJ, Song BW, Ham O, Lee SY, Lee $\mathrm{C}$, et al. PLCdeltal protein rescues ischemia-reperfused heart by the regulation of calcium homeostasis. Mol Ther. 2014;22(6):1110-1121.

13. Pandit A, Mookadam F, Hakim FA, Mulroy E, Saadiq R, Doherty M, Cha S, et al. Ia Diastolic Dysfunction: An Echocardiographic Grade. Echocardiography. 2014.

14. Afolabi-Brown OO, Lynn Morris D, Pressman GS. Systolic mitral valve opening and absent isovolumic relaxation: unusual hemodynamics of severe mitral regurgitation. Echocardiography. 2014;31(6):E189-190.

15. Pouleur H. Diastolic dysfunction and myocardial energetics. Eur Heart J. 1990;11(Suppl C):30-34.

16. Tzschatzsch H, Hattasch R, Knebel F, Klaua R, Schultz $\mathrm{M}$, Jenderka KV, Braun J, et al. Isovolumetric elasticity alteration in the human heart detected by in vivo time-harmonic elastography. Ultrasound Med Biol. 2013;39(12):2272-2278.

17. Frais MA, Bergman DW, Kingma I, Smiseth OA, Smith ER, Tyberg JV. The dependence of the time constant of left ventricular isovolumic relaxation (tau) on pericardial pressure. Circulation. 1990;81(3):1071-1080.

18. Gaasch WH, Blaustein AS, Andrias CW, Donahue RP, Avitall B. Myocardial relaxation. II. Hemodynamic determinants of rate of left ventricular isovolumic pressure decline. Am J Physiol. 1980;239(1):H1-6.

19. Zile MR, Gaasch WH. Mechanical loads and the isovolumic and filling indices of left ventricular relaxation. Prog Cardiovasc Dis. 1990;32(5):333-346.

20. Pfaffenberger S, Bartko P, Graf A, Pernicka E, Babayev J, Lolic E, Bonderman D, et al. Size matters! Impact of age, sex, height, and weight on the normal heart size. Circ Cardiovasc Imaging. 2013;6(6):1073-1079.

21. Miyoshi H, Oishi Y, Mizuguchi Y, Iuchi A, Nagase N, Ara N, Oki T. Influence of comorbid cardiovascular risk factors on left atrial-left ventricular interaction in asymptomatic patients: clinical application of two-dimensional speckle-tracking echocardiography. Int Heart J. 2014;55(2):138-145.

22. Krzesiak-Lodyga A, Cwetsch A. [Echocardiographic methods for assessment of left ventricular diastolic dysfunction--state of the art]. Pol Merkur Lekarski. 2013;35(206):63-66.

23. Zile MR, Gaasch WH, Carroll JD, Feldman MD, Aurigemma GP, Schaer GL, Ghali JK, et al. Heart failure with a normal ejection fraction: is measurement of diastolic function necessary to make the diagnosis of diastolic heart failure? Circulation. 2001;104(7):779-782.

24. Lang RM, Bierig M, Devereux RB, Flachskampf FA, Foster E, Pellikka PA, Picard MH, et al. Recommendations for chamber quantification: a report from the American Society of Echocardiography's Guidelines and Standards Committee and the Chamber Quantification Writing Group, developed in conjunction with the European Association of Echocardiography, a branch of the European Society of Cardiology. J Am Soc Echocardiogr. 
2005;18(12):1440-1463.

25. Vasan RS, Larson MG, Benjamin EJ, Evans JC, Reiss CK, Levy D. Congestive heart failure in subjects with normal versus reduced left ventricular ejection fraction: prevalence and mortality in a population-based cohort. J Am Coll Cardiol. 1999;33(7):1948-1955.

26. Eichhorn EJ, Willard JE, Alvarez L, Kim AS, Glamann DB, Risser RC, Grayburn PA. Are contraction and relaxation coupled in patients with and without congestive heart failure? Circulation. 1992;85(6):2132-2139.

27. Naqvi TZ, Neyman G, Broyde A, Mustafa J, Siegel RJ. Comparison of myocardial tissue Doppler with transmitral flow Doppler in left ventricular hypertrophy. J Am Soc Echocardiogr. 2001;14(12):1153-1160.

28. Schannwell CM, Schneppenheim M, Plehn G, Marx R, Strauer BE. Left ventricular diastolic function in physiologic and pathologic hypertrophy. Am J Hypertens. 2002;15(6):513-517.

29. Schillaci G, Pasqualini L, Verdecchia P, Vaudo G, Marchesi S, Porcellati C, de Simone G, et al. Prognostic significance of left ventricular diastolic dysfunction in essential hypertension. J Am Coll Cardiol. 2002;39(12):20052011.

30. Harizi RC, Bianco JA, Alpert JS. Diastolic function of the heart in clinical cardiology. Arch Intern Med. 1988;148(1):99-109.

31. Garcia MJ, Smedira NG, Greenberg NL, Main M, Firstenberg MS, Odabashian J, Thomas JD. Color M-mode Doppler flow propagation velocity is a preload insensitive index of left ventricular relaxation: animal and human validation. J Am Coll Cardiol. 2000;35(1):201-208.

32. Ommen SR, Nishimura RA, Appleton CP, Miller FA, Oh JK, Redfield MM, Tajik AJ. Clinical utility of Doppler echocardiography and tissue Doppler imaging in the estimation of left ventricular filling pressures: A comparative simultaneous Doppler-catheterization study. Circulation. 2000;102(15):1788-1794.

33. De Boeck BW, Oh JK, Vandervoort PM, Vierendeels JA, van der Aa RP, Cramer MJ. Colour M-mode velocity propagation: a glance at intra-ventricular pressure gradients and early diastolic ventricular performance. Eur J Heart Fail. 2005;7(1):19-28.

34. Chamoun AJ, Xie T, McCullough M, Birnbaum Y, Ahmad M. Color M-mode flow propagation velocity and conventional doppler indices in the assessment of diastolic left ventricular function during isometric exercise. Echocardiography. 2005;22(5):380-388.

35. Bermejo J, Antoranz JC, Yotti R, Moreno M, GarciaFernandez MA. Spatio-temporal mapping of intracardiac pressure gradients. A solution to Euler's equation from digital postprocessing of color Doppler M-mode echocardiograms. Ultrasound Med Biol. 2001;27(5):621-630.

36. Greenberg NL, Vandervoort PM, Firstenberg MS, Garcia MJ, Thomas JD. Estimation of diastolic intraventricular pressure gradients by Doppler M-mode echocardiography. Am J Physiol Heart Circ Physiol. 2001;280(6):H25072515.

37. Firstenberg MS, Smedira NG, Greenberg NL, Prior DL,
McCarthy PM, Garcia MJ, Thomas JD. Relationship between early diastolic intraventricular pressure gradients, an index of elastic recoil, and improvements in systolic and diastolic function. Circulation. 2001;104(12 Suppl 1):I330-335.

38. Xie GY, Berk MR, Smith MD, Gurley JC, DeMaria AN. Prognostic value of Doppler transmitral flow patterns in patients with congestive heart failure. J Am Coll Cardiol. 1994;24(1):132-139.

39. Rihal CS, Nishimura RA, Hatle LK, Bailey KR, Tajik AJ. Systolic and diastolic dysfunction in patients with clinical diagnosis of dilated cardiomyopathy. Relation to symptoms and prognosis. Circulation. 1994;90(6):2772-2779.

40. Traversi E, Pozzoli M, Cioffi G, Capomolla S, Forni G, Sanarico M, Tavazzi L. Mitral flow velocity changes after 6 months of optimized therapy provide important hemodynamic and prognostic information in patients with chronic heart failure. Am Heart J. 1996;132(4):809-819.

41. Giannuzzi P, Temporelli PL, Bosimini E, Silva P, Imparato A, Corra U, Galli M, et al. Independent and incremental prognostic value of Doppler-derived mitral deceleration time of early filling in both symptomatic and asymptomatic patients with left ventricular dysfunction. J Am Coll Cardiol. 1996;28(2):383-390.

42. Hurrell DG, Oh JK, Mahoney DW, Miller FA, Jr., Seward JB. Short deceleration time of mitral inflow E velocity: prognostic implication with atrial fibrillation versus sinus rhythm. J Am Soc Echocardiogr. 1998;11(5):450-457.

43. Hansen A, Haass M, Zugck C, Krueger C, Unnebrink K, Zimmermann R, Kuebler W, et al. Prognostic value of Doppler echocardiographic mitral inflow patterns: implications for risk stratification in patients with chronic congestive heart failure. J Am Coll Cardiol. 2001;37(4):10491055.

44. Faris R, Coats AJ, Henein MY. Echocardiography-derived variables predict outcome in patients with nonischemic dilated cardiomyopathy with or without a restrictive filling pattern. Am Heart J. 2002;144(2):343-350.

45. Whalley GA, Doughty RN, Gamble GD, Wright SP, Walsh HJ, Muncaster SA, Sharpe N. Pseudonormal mitral filling pattern predicts hospital re-admission in patients with congestive heart failure. J Am Coll Cardiol. 2002;39(11):1787-1795.

46. Rossi A, Cicoira M, Golia G, Zanolla L, Franceschini L, Marino P, Graziani M, et al. Amino-terminal propeptide of type III procollagen is associated with restrictive mitral filling pattern in patients with dilated cardiomyopathy: a possible link between diastolic dysfunction and prognosis. Heart. 2004;90(6):650-654.

47. Bella JN, Palmieri V, Roman MJ, Liu JE, Welty TK, Lee ET, Fabsitz RR, et al. Mitral ratio of peak early to late diastolic filling velocity as a predictor of mortality in middle-aged and elderly adults: the Strong Heart Study. Circulation. 2002;105(16):1928-1933.

48. Pozzoli M, Traversi E, Cioffi G, Stenner R, Sanarico M, Tavazzi L. Loading manipulations improve the prognostic value of Doppler evaluation of mitral flow in patients with chronic heart failure. Circulation. 1997;95(5):1222- 
1230.

49. Pinamonti B, Zecchin M, Di Lenarda A, Gregori D, Sinagra G, Camerini F. Persistence of restrictive left ventricular filling pattern in dilated cardiomyopathy: an ominous prognostic sign. J Am Coll Cardiol. 1997;29(3):604-612.

50. Temporelli PL, Corra U, Imparato A, Bosimini E, Scapellato F, Giannuzzi P. Reversible restrictive left ventricular diastolic filling with optimized oral therapy predicts a more favorable prognosis in patients with chronic heart failure. J Am Coll Cardiol. 1998;31(7):1591-1597.

51. Oh JK, Ding ZP, Gersh BJ, Bailey KR, Tajik AJ. Restrictive left ventricular diastolic filling identifies patients with heart failure after acute myocardial infarction. J Am Soc Echocardiogr. 1992;5(5):497-503.

52. Pozzoli M, Capomolla S, Sanarico M, Pinna G, Cobelli F, Tavazzi L. Doppler evaluations of left ventricular diastolic filling and pulmonary wedge pressure provide similar prognostic information in patients with systolic dysfunction after myocardial infarction. Am Heart J. 1995;129(4):716-725.

53. Nijland F, Kamp O, Karreman AJ, van Eenige MJ, Visser CA. Prognostic implications of restrictive left ventricular filling in acute myocardial infarction: a serial Doppler echocardiographic study. J Am Coll Cardiol. 1997;30(7):1618-1624.

54. Sakata K, Kashiro S, Hirata S, Yanagisawa A, Ishikawa K. Prognostic value of Doppler transmitral flow velocity patterns in acute myocardial infarction. Am J Cardiol. 1997;79(9):1165-1169.

55. Somaratne JB, Whalley GA, Gamble GD, Doughty RN. Restrictive filling pattern is a powerful predictor of heart failure events postacute myocardial infarction and in established heart failure: a literature-based meta-analysis. J Card Fail. 2007;13(5):346-352.

56. Poulsen SH, Jensen SE, Gotzsche O, Egstrup K. Evaluation and prognostic significance of left ventricular diastolic function assessed by Doppler echocardiography in the early phase of a first acute myocardial infarction. Eur Heart J. 1997;18(12):1882-1889.

57. Dini FL, Michelassi C, Micheli G, Rovai D. Prognostic value of pulmonary venous flow Doppler signal in left ventricular dysfunction: contribution of the difference in duration of pulmonary venous and mitral flow at atrial contraction. J Am Coll Cardiol. 2000;36(4):1295-1302.

58. Dini FL, Dell'Anna R, Micheli A, Michelassi C, Rovai D. Impact of blunted pulmonary venous flow on the outcome of patients with left ventricular systolic dysfunction secondary to either ischemic or idiopathic dilated cardiomyopathy. Am J Cardiol. 2000;85(12):1455-1460.

59. Moller JE, Sondergaard E, Seward JB, Appleton CP, Egstrup K. Ratio of left ventricular peak E-wave velocity to flow propagation velocity assessed by color M-mode Doppler echocardiography in first myocardial infarction: prognostic and clinical implications. J Am Coll Cardiol. 2000;35(2):363-370.

60. Moller JE, Sondergaard E, Poulsen SH, Egstrup K. Pseudonormal and restrictive filling patterns predict left ventricular dilation and cardiac death after a first myocardial infarction: a serial color M-mode Doppler echocardiographic study. J Am Coll Cardiol. 2000;36(6):1841-1846.

61. Moller JE, Sondergaard E, Poulsen SH, Seward JB, Appleton CP, Egstrup K. Color M-mode and pulsed wave tissue Doppler echocardiography: powerful predictors of cardiac events after first myocardial infarction. J Am Soc Echocardiogr. 2001;14(8):757-763.

62. Troughton RW, Prior DL, Frampton CM, Nash PJ, Pereira JJ, Martin M, Fogarty A, et al. Usefulness of tissue doppler and color M-mode indexes of left ventricular diastolic function in predicting outcomes in systolic left ventricular heart failure (from the ADEPT study). Am J Cardiol. 2005;96(2):257-262.

63. Wang M, Yip GW, Wang AY, Zhang Y, Ho PY, Tse MK, Lam PK, et al. Peak early diastolic mitral annulus velocity by tissue Doppler imaging adds independent and incremental prognostic value. J Am Coll Cardiol. 2003;41(5):820-826.

64. Yamamoto T, Oki T, Yamada H, Tanaka H, Ishimoto T, Wakatsuki T, Tabata T, et al. Prognostic value of the atrial systolic mitral annular motion velocity in patients with left ventricular systolic dysfunction. J Am Soc Echocardiogr. 2003;16(4):333-339.

65. Redfield MM, Jacobsen SJ, Burnett JC, Jr., Mahoney DW, Bailey KR, Rodeheffer RJ. Burden of systolic and diastolic ventricular dysfunction in the community: appreciating the scope of the heart failure epidemic. JAMA. 2003;289(2):194-202.

66. Hillis GS, Moller JE, Pellikka PA, Gersh BJ, Wright RS, Ommen SR, Reeder GS, et al. Noninvasive estimation of left ventricular filling pressure by E/e' is a powerful predictor of survival after acute myocardial infarction. J Am Coll Cardiol. 2004;43(3):360-367.

67. Wang M, Yip G, Yu CM, Zhang Q, Zhang Y, Tse D, Kong $\mathrm{SL}$, et al. Independent and incremental prognostic value of early mitral annulus velocity in patients with impaired left ventricular systolic function. J Am Coll Cardiol. 2005;45(2):272-277.

68. Dokainish H, Zoghbi WA, Lakkis NM, Ambriz E, Patel R, Quinones MA, Nagueh SF. Incremental predictive power of B-type natriuretic peptide and tissue Doppler echocardiography in the prognosis of patients with congestive heart failure. J Am Coll Cardiol. 2005;45(8):1223-1226.

69. Wang M, Yip GW, Wang AY, Zhang Y, Ho PY, Tse MK, Yu CM, et al. Tissue Doppler imaging provides incremental prognostic value in patients with systemic hypertension and left ventricular hypertrophy. J Hypertens. 2005;23(1):183-191.

70. Sharma R, Pellerin D, Gaze DC, Mehta RL, Gregson H, Streather CP, Collinson PO, et al. Mitral peak Doppler Ewave to peak mitral annulus velocity ratio is an accurate estimate of left ventricular filling pressure and predicts mortality in end-stage renal disease. J Am Soc Echocardiogr. 2006;19(3):266-273.

71. Okura H, Takada Y, Kubo T, Iwata K, Mizoguchi S, Taguchi H, Toda I, et al. Tissue Doppler-derived index of left ventricular filling pressure, E/E', predicts survival of patients with non-valvular atrial fibrillation. Heart. 
2006;92(9):1248-1252.

72. Bruch C, Klem I, Breithardt G, Wichter T, Gradaus R. Diagnostic usefulness and prognostic implications of the mitral $\mathrm{E} / \mathrm{E}^{\prime}$ ratio in patients with heart failure and severe secondary mitral regurgitation. Am J Cardiol. 2007;100(5):860-865.

73. McMahon CJ, Nagueh SF, Pignatelli RH, Denfield SW, Dreyer WJ, Price JF, Clunie S, et al. Characterization of left ventricular diastolic function by tissue Doppler imaging and clinical status in children with hypertrophic cardiomyopathy. Circulation. 2004;109(14):1756-1762.

74. McMahon CJ, Nagueh SF, Eapen RS, Dreyer WJ, Finkelshtyn I, Cao X, Eidem BW, et al. Echocardiographic predictors of adverse clinical events in children with dilated cardiomyopathy: a prospective clinical study. Heart. 2004;90(8):908-915.

75. Tsang TS, Barnes ME, Gersh BJ, Bailey KR, Seward JB. Left atrial volume as a morphophysiologic expression of left ventricular diastolic dysfunction and relation to cardiovascular risk burden. Am J Cardiol. 2002;90(12):12841289.

76. Cameli M, Lisi M, Focardi M, Reccia R, Natali BM, Sparla S, Mondillo S. Left atrial deformation analysis by speckle tracking echocardiography for prediction of cardiovascular outcomes. Am J Cardiol. 2012;110(2):264269.

77. O'Rourke MF. The arterial pulse in health and disease. Am Heart J. 1971;82(5):687-702.

78. Brilla CG, Janicki JS, Weber KT. Impaired diastolic function and coronary reserve in genetic hypertension. Role of interstitial fibrosis and medial thickening of intramyocardial coronary arteries. Circ Res. 1991;69(1):107-115.

79. Emoto M, Nishizawa Y, Kawagishi T, Maekawa K, Hiura Y, Kanda H, Izumotani K, et al. Stiffness indexes beta of the common carotid and femoral arteries are associated with insulin resistance in NIDDM. Diabetes Care. 1998;21(7):1178-1182.

80. Palmiero P, Maiello M, Daly DD, Jr., Ciccone MM, Nanda NC. Aortic stiffness assessed by global pulse wave velocity in postmenopausal women: an ultrasonographic study. Echocardiography. 2012;29(10):1233-1238.

81. Laurent S, Alivon M, Beaussier H, Boutouyrie P. Aortic stiffness as a tissue biomarker for predicting future cardiovascular events in asymptomatic hypertensive subjects. Ann Med. 2012;44(Suppl 1):S93-97.

82. Coutinho T, Turner ST, Kullo IJ. Aortic pulse wave velocity is associated with measures of subclinical target organ damage. JACC Cardiovasc Imaging. 2011;4(7):754-761.

83. Gosling RG, Budge MM. Terminology for describing the elastic behavior of arteries. Hypertension. 2003;41(6):1180-1182.
84. Bortolotto LA, Blacher J, Kondo T, Takazawa K, Safar ME. Assessment of vascular aging and atherosclerosis in hypertensive subjects: second derivative of photoplethysmogram versus pulse wave velocity. Am J Hypertens. 2000;13(2):165-171.

85. Banks K, Puttagunta D, Murphy S, Lo M, McGuire DK, de Lemos JA, Chang AY, et al. Clinical characteristics, vascular function, and inflammation in women with angina in the absence of coronary atherosclerosis: the Dallas Heart Study. JACC Cardiovasc Imaging. 2011;4(1):6573.

86. Georgianos PI, Sarafidis PA, Malindretos P, Nikolaidis P, Lasaridis AN. Hemodialysis reduces augmentation index but not aortic or brachial pulse wave velocity in dialysisrequiring patients. Am J Nephrol. 2011;34(5):407-414.

87. Blacher J, Guerin AP, Pannier B, Marchais SJ, Safar ME, London GM. Impact of aortic stiffness on survival in endstage renal disease. Circulation. 1999;99(18):2434-2439.

88. Greenwald SE. Ageing of the conduit arteries. J Pathol. 2007;211(2):157-172.

89. Safar ME, Laurent S, Pannier BM, London GM. Structural and functional modifications of peripheral large arteries in hypertensive patients. J Clin Hypertens. 1987;3(3):360-367.

90. Baguet JP, Kingwell BA, Dart AL, Shaw J, Ferrier KE, Jennings GL. Analysis of the regional pulse wave velocity by Doppler: methodology and reproducibility. J Hum Hypertens. 2003;17(6):407-412.

91. Chung CM, Lin YS, Chu CM, Chang ST, Cheng HW, Yang TY, Hsiao JF, et al. Arterial stiffness is the independent factor of left ventricular hypertrophy determined by electrocardiogram. Am J Med Sci. 2012;344(3):190193.

92. Benetos A, Laurent S, Hoeks AP, Boutouyrie PH, Safar ME. Arterial alterations with aging and high blood pressure. A noninvasive study of carotid and femoral arteries. Arterioscler Thromb. 1993;13(1):90-97.

93. Sowers MF, Karvonen-Gutierrez CA, Yosef M, Jannausch M, Jiang Y, Garnero P, Jacobson J. Longitudinal changes of serum COMP and urinary CTX-II predict X-ray defined knee osteoarthritis severity and stiffness in women. Osteoarthritis Cartilage. 2009;17(12):1609-1614.

94. Coutinho T, Borlaug BA, Pellikka PA, Turner ST, Kullo IJ. Sex differences in arterial stiffness and ventricular-arterial interactions. J Am Coll Cardiol. 2013;61(1):96-103.

95. Okamura T, Moriyama Y, Kadowaki T, Kanda H, Ueshima H. Non-invasive measurement of brachial-ankle pulse wave velocity is associated with serum C-reactive protein but not with alpha-tocopherol in Japanese middle-aged male workers. Hypertens Res. 2004;27(3):173-180. 